\title{
Danger and opportunity
}

\author{
The response to the financial crisis needs to go beyond the immediate pressures. Policy-makers must seize \\ this moment to solidify the science and innovation required for sustained economic growth.
}

"W hile innovation is commonly associated with growth, it is now more correctly pinned to survival." That was one conclusion from a meeting convened in Dubai last weekend by the World Economic Forum, a body best known for its annual summit in Davos, Switzerland. It is correct: with an economic crisis of unknown proportions looming, more emphasis on science and innovation - not less - will be crucial to achieving a sustained recovery.

Over the past few decades the world has built up a formidable science and innovation complex. Among countries in the Organisation for Economic Co-operation and Development, funding for research and development (R\&D) alone almost doubled from US\$468 billion in 1996 to $\$ 818$ billion in 2006 - although growth has been slowing since 2001, particularly in the United States. Globalization has given rise to major new players in research, such as China and India, as well as to transnational webs of R\&D centres and company subsidiaries. And, perhaps most important, many countries have developed increasingly sophisticated innovation policies. These include support for education at every level; for robust capital markets; for reliable energy, transportation and communications infrastructures; and for all the other tightly interlinked factors that contribute to innovation, and which in turn affect what happens in the economy.

The present financial crisis is placing multiple strains on this web, as a Special Report on page 155 makes clear. National funding for research is under pressure as governments face falling tax revenues and the need for massive financial-stimulus measures. Universities' funding and endowments are shrinking. The crisis in confidence among banks could spread, creating a risk-averse investment culture that would starve high-tech start-up firms and other businesses of capital.

Taken together, such threats could prove a setback to the progress made in building global innovation systems. Policy-makers should instead take every step possible to reinforce those systems.

In coming months they will have to balance many legitimate demands on the public purse, including the need to relieve their citizen's immediate economic pain, and resuscitate economic demand with tax cuts and public spending. Such needs will become acute if the global recession is deep and prolonged, especially in countries with already weak economies, and will have to take priority.

\section{Future investments}

Nonetheless, policy-makers also have a responsibility to take the long view. High-tech companies have long known that protecting R\&D is key to coming out of a recession strong; they tend to cut everything else first. It's encouraging that many governments - large and small — are now taking a similar view: education and research are not merely costs to be cut, but investments in long-term economic recovery. Whether governments live up to this rhetoric is another matter, but they would be irresponsible to undertake large stimulus efforts without also providing for long-term growth to reduce the resulting deficits.

Also encouraging is the emerging appreciation that short- and long-term measures to address the economic crisis need not be mutually exclusive. Often they can and should be considered simultaneously. After trillion-dollar rescues of the banking system, for example, many countries are indeed contemplating massive economic stimulus packages. But instead of crafting conventional, spendingoriented plans focused solely on tax cuts
"Education and research are not merely costs to be cut, but investments in long-term economic recovery." for individuals and spending increases, policy-makers should look for ways to give the economy a quick shot in the arm while also boosting investment that spurs productivity, growth and innovation.

China seems to be thinking in those terms. Last weekend, Beijing announced a 4-trillion-yuan (US\$586-billion) stimulus package, at least some of which - details remain vague - will go on research tax credits and investments in infrastructure. The United States, which is debating a stimulus package of similar magnitude, may do likewise: Barack Obama, the US president-elect, campaigned on the need for major investments in clean energy, education, health and infrastructure, most of which will have a strong research component.

\section{Innovative thinking}

Good specific ideas are emerging. On 29 October, for example, the Information Technology \& Innovation Foundation, a think tank based in Washington DC, outlined eight possibilities in the IT realm. Among them were increased grants for universities to buy research equipment in 2009, a tax credit for investments in energy-efficient equipment in 2009 and billions of dollars to buy computers and broadband for lowincome families with children at home. In the area of clean energy, meanwhile, others have suggested the use of stimulus money to spur demand for new technologies, much as consumer subsidies to use solar energy in Germany have helped drive the growth of solar start-ups not only in that country, but also in the United States and China.

Indeed, the crisis is providing multiple opportunities for governments to take decisive action on innovation, and policy-makers should champion those possibilities as they hammer out stimulus packages. Given the deeply intertwined nature of the modern global innovation system, they should act collaboratively — as they have already begun to do in addressing the problems of the global financial system. International cooperation at this level has been all too rare in recent years. But there is every reason to hope that the experience provided by this crisis will be a model for future efforts to combat challenges such as climate change and water shortage by a world aptly described by Obama in his victory speech as "connected by our own science and imagination". 